\title{
La extinción del oficio del escritor en Notas de un ventrílocuo de Germán Marín
}

\section{The extinction of the writer's trade in Notas de un ventrilocuo by Germán Marín}

Mariela Fuentes LeAL

Universidad de Concepción, Chile.

mariefue@udec.cl

T a novela Notas de un ventrilocuo (2013) de Germán Marín continúa Luno de los proyectos más significativos y experimentales de la narrativa chilena actual. El texto compuesto, por una serie de fragmentos, a modo de diario de vida, de un ventrílocuo solitario, reflexivo y anacrónico, abarca un extenso período histórico, enfocado en la cultura del espectáculo chilena, desde los años cuarenta del siglo XX hasta el presente. La novela está narra$\mathrm{da}$, con un tono de resignación y derrota, por un protagonista anónimo y de edad conjetural, que ha sido desplazado hacia los márgenes de la cultura en el avance de la modernidad. El propio Marín expone en una entrevista "así como he visto desaparecer al fotógrafo ambulante, al organillero, al afilador de cuchillos, el ventrílocuo es un artista menor que se ha extinguido del escenario, originario de la Grecia clásica, debido, entre otros aspectos, al cambio de la noción del espectáculo" (Alarcón, 2013). Frente a esto, el narrador renombra este término y la llama "cultura del desalojo", la cual está basada en estrategias de marketing ligadas a la publicidad y caracterizada por la artificialidad de eventos artísticos y la simulación de un público atento.

En efecto, el propio autor ha señalado que esta obra es "una novela de un Chile perdido y de oficios perdidos" (Careaga, 2013: 48). Así, Notas de un ventrílocuo es un texto elaborado a partir de la pérdida de una época ida, caracterizada por una oferta cultural heterogénea y multiplicada, opuesta a la actual, donde el sentido de profesiones de antaño queda relegado a los 
márgenes; pero que la obra mariniana visibiliza a través de la memoria fragmentaria de un ventrílocuo observador y polifacético descrito, por el crítico Pedro Gandolfo, como "un personaje de identidad incierta -amante, escritor, cronista, bohemio, crítico, lector, ocioso-, identidad que, por cierto, sintoniza con los distintos muñecos que emplea en sus actuaciones el ventrílocuo y para quienes él mismo redacta sus diálogos" (2013: 16). Así, la estructura de la novela está dividida en dos capítulos: "Mesa revuelta" y "Papel mojado", cuyo funcionamiento es metafórico, ya que sus nombres representan un proceso de escritura desordenado en la memoria y trastocado en el tiempo a causa de las transformaciones técnicas, culturales y sociopolíticas, que han repercutido a tal punto en la existencia del protagonista extemporáneo que han hecho que "transcurra bajo cierto grado cero de vida" (103).

Ciertamente, Germán Marín está acostumbrado a escribir desde el otro,

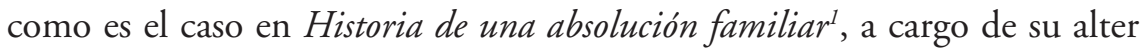
ego Venzano Torres, donde conjuga vida y ficción en tres planos narrativos: una historia narrada, un diario de vida y notas de aquél. En el caso de este último libro, el arte de la ventriloquia otorga la palabra a "otros", mediante el desdoblamiento continúo e itinerante del protagonista, quien escribe sus apuntes con una escritura abierta, que permite una multiplicidad de voces, dirigidas hacia un pretérito menoscabado en el tiempo, que "no se detiene y, mientras morimos, avanza al igual que el reloj desplazándonos día y noche hacia el pasado" (68). Así, Marín utiliza el arte de la ventriloquia para dar voz a un artista de un arte menor, hoy prácticamente desaparecido, quien se desdobla a través de sus muñecos (Tonino, Don Beto, Adolfito, Guayo, Apolonio e Hilario), ahora maltratados y envejecidos, e inculpa, en primera instancia, al golpe militar de 1973 por fracturar la cartografía artística chilena, donde "Pinochet fue un ventrílocuo frente a Allende" (99), y en segunda instancia, al avance de la tecnología que ha llevado a una decadencia en el arte, de modo que "hoy se estima que otra es su conducta, al punto a veces de sospecharse que, tras su artificial interés al espectáculo, sólo participa bajo la simulación de aparecer como niños"(39).

Así también, el ventrílocuo extiende su habla hacia Marín, en tanto "el otro es el muñeco que tiene el ventrílocuo, así como el personaje que crea el novelista" (17). De esta manera, el personaje es el ventrílocuo del autor que emplea fragmentos de su vida como material de arte en busca de respuestas ante la empresa del espectáculo en la Posmodernidad. De esta manera, ambos están a las orillas de la sociedad del espectáculo actual y resisten actuali-

${ }^{1}$ Trilogía compuesta por Círculo vicioso (1994), Las cien águilas (1997) y La ola muerta (2005). 
zarse; por una parte, el personaje tiene una escasez de ofertas laborales, pero a pesar de ello no duda en permanecer en su labor de ventrílocuo: "debo proseguir mi oficio, languideciente como está, pero que aún le concede un proyecto a mi humanidad envejecida, aunque viviente todavía" (57); por su parte, Marín se aísla en la ciudad de Santiago, retratada como un centro hecho por la derrota y sin identidad en el texto, por varias razones; entre otras, el crepúsculo de la vida a nivel del espectáculo y el desarrollo de la tecnología "la idea de escribir esta novela apareció de la congestión de ver el mundo sumergido en el avance tecnológico, sin otro modo de ver todo como un futuro alienado" (Alarcón, 2013).

Por lo anterior, nos parece apropiado leer la novela desde el concepto de "literatura escribivida", definida por Germán Marín como un discurso que fusiona los términos "escritura" y "vida", en tanto búsqueda incesante de trozos comunicantes que reconstruyen: por un lado, el pasado de Chile, principalmente, en la dimensión cultural. Por ejemplo, la novela es un documento valioso con antecedentes fácticos de la vida del espectáculo santiaguina como: el Teatro Municipal de Santiago, Marconi, Rialto, Astor, la Bôite Casanova, Tap Room, Tropicana Club, El Rosedal, Bim Bam Bum, Lucerna, entre otros. Por otro lado, es una escritura de resistencia a la digitalización, nacida como ejercicio manuscrito, vinculado a lo corpóreo, viviente y creativo, abandonado cuando usó la máquina de escribir Olivetti Lettera 22, pero retomado cuando ésta se daña irreparablemente: "haber regresado a este ejercicio, bajo el cual prosigo hasta hoy, tiene en sí una forma más entrañable de estampar las palabras, más íntima, en que el cuerpo, representado por la mano empuñada en un bolígrafo, es el que escribe el dictado invisible sobre el papel” (58). Así, el proceso de escritura se complejiza y la literatura se desplaza fuera del espacio literario: hacia la vida.

En este sentido, aproximamos la escritura mariniana a la idea de pliegue de Gilles Deleuze en su libro El pliegue: Leibniz y el Barroco (1989), porque "el objeto ya no se define por una forma esencial, sino que alcanza la funcionalidad pura (...) con la modulación temporal que implica tanto una puesta en variación continua de la materia como un desarrollo continuo de la forma" (30). En otras palabras, el libro es como un pliegue de un proyecto incesante con una escritura polimorfa y polivalente, sin lineamientos cronológicos, en busca de lo viviente, misterioso e incesante, carente de censuras ni inhibiciones; es decir, la vida misma. Así, leemos "como se advierte, la novela está escrita desde un presente, en que incluso el pasado es una actualización, un calendario sin fin, como los hechos que se relatan" (Alarcón, 2013).

De esta manera, el registro narrativo mariniano trabaja con la noción de 
tiempo como un devenir, el que "avanza mientras retrocede"2. En este sentido, funcionalizamos la metáfora del $\mathrm{ADN}^{3}$,como un mecanismo estético y creativo, para entender su narrativa como una doble espiral que entrecruza dimensiones antagónicas y construye una escritura trazada como una curva de paradojas que arrastra al escritor hacia la ausencia del tiempo histórico, en una indeterminación entre la memoria y la imaginación. En palabras de Maurice Blanchot "pareciera que el tiempo dispersado por una secreta catástrofe interior, deja que segmentos del porvenir se hagan vislumbrar en medio del presente o que entren en libre comunicación con el pasado. El tiempo soñado, el tiempo recordado, el tiempo que hubiese podido ser $\mathrm{y}$, por último, el futuro se transforma incesantemente en la presencia radiante del espacio, lugar de expansión de la pura visibilidad" (1992: 183).

De este modo, Marín da a entender que el pasado es parte del presente $y$ del futuro en un incesante devenir que mantiene vigente su proyecto de escritura inacabado en el cual revive personajes desarrollados en obras anteriores como La Bambi, La Princesa del Babilonia en un relato con el mismo nombre en una edición no venal ${ }^{4}$ y publicado luego en Basuras de Shanghai (2007) y Betty Catrileo en La ola muerta (2005) y Dejar hacer (2010), quienes han perdido el esplendor de años pasados, pero que, al igual que el protagonista, tratan de mantenerse vigentes en espacios del espectáculo nocturno de Santiago. Así también, el autor ficcionaliza la realidad cuando evoca a Enrique Lihn y Jorge Teillier, este último aparece una figura espectral que visita al protagonista en la realidad (116). Incluso, Marín juega con un presente prospectivo cuando narra la historia de un libro futuro no publicado, dado a conocer en entrevistas, ambientado en el norte de Chile sobre la existencia del chupacabras: "he seguido con interés (...) el relato hecho por un periodista amigo de Hidalgo que, de vuelta de Coquimbo, me ha contado, mientras bebíamos el primer trago, sobre la existencia del llamado chupacabras" (66).

Por lo tanto, nos parece que los apuntes del ventrílocuo son mecanismos tanto de sobrevivencia, de resistencia frente a la inacción del presente que ha causado un enajenamiento de lo humano por los avances tecnológicos, ya que "resulta confuso pretender alguna afirmación sobre el propósito alber-

${ }^{2}$ También, este mecanismo está presente en su trilogía Historia de una absolución familiar, donde el autor/narrador/personaje deviene cangrejo (1997: 12), crustáceo (1994: 72), hipopótamo (1994: 248) y pájaro: (1994: 240).

${ }^{3}$ La metáfora del ADN la desarrollamos en nuestro artículo "En busca del ADN de la escritura en Historia de una absolución familiar de Germán Marín” (Fuentes Leal, 2010: 9-33).

${ }^{4}$ La princesa del Babilonia es un relato de publicación anticipada de 100 ejemplares en una edición no venal. 
gado, excepto de mi parte ampliar que he garrapateado sin plan alguno, a la deriva del mundo circundante, dedicado sin más a los dictados del día o, a veces, a la mirada vuelta hacia atrás" (72); y, del mismo modo, situarse en la vacío del hoy, en tanto "a menudo me distraigo viendo la televisión, sobre todo porque no me deja nada, reducido a un estado presente que excluye cualquier huella posterior" (81).

Finalmente, es significativa la relación que se establece en la novela entre el arte de la ventriloquia y el literario; el primero, a cargo de un artista menor que permanece como residuo del pasado en la actualidad y, el segundo, construido como un ejercicio menor abocado a un número reducido de personas, ya que "el escritor va a terminar y la novela y la poesía van a ser artes menores. Va a ver otras configuraciones (...) la gente que lee y escribe se está reduciendo. Es muy rica, muy inteligente, pero va terminando siendo una élite" (Guerrero, 2013: 12).

En relación al planteamiento crítico realizado por Marín, de la actual crisis de la cultura del espectáculo y del desplazamiento de la literatura hacia una élite, es valioso trazar una intertextualidad entre la narrativa de Germán Marín y la dramaturgia de Vicente Huidobro, cuando el protagonista de Notas de un ventrílocuo realiza una reflexión sobre el uso de la palabra "chic" y lo menciona como parte de la élite chilena entrecruzada de origen castellanovasco que quería ser francesa en un "mundo claustrofílico satisfecho de vivir" (68). Más adelante, ese grupo es descompuesto por una crisis originada por una serie de transformaciones en el país, que llevan a un desuso de la palabra: "quedó atrás definitivamente, muerta en el vocabulario de una élite, reemplazada hoy por unos términos más abiertos socialmente, aunque no menos extranjerizantes, que me molestan al revisar mis templados libretos dedicados a escenificar" (69). Por su parte, Vicente Huidobro escenifica la figura del ventrílocuo en su obra de teatro llamada En la luna de 1934, en el Acto I, contextualizada en una compleja época envuelta por grandes cambios culturales en la realidad de Chile. El personaje Maese López señala "ya no os traigo a aquel famoso ventrílocuo, ¿̇recordáis? Que sacaba la voz del bolsillo del más lejano espectador y sólo con la voz le sacaba la cartera o el reloj. Os juro que todo lo que ahora traigo es nuevo y que no se ha visto jamás en la Luna un espectáculo superior" (466). De esta manera, hay una aproximación entre Marín y Huidobro cuando ambos reflexionan sobre figuras del pretérito (el lenguaje y el ventrílocuo) que aparecen como "desajustados" en el tiempo actual, pero que representaron un apreciado aporte en el espectáculo del pasado, en tanto generaban asombro y vínculo con la ficción de una realidad vinculada a la voz humana. En el caso de Huidobro, el ventrílocuo del teatro es reemplazado por 
muñecos y títeres del guiñol que parodian los hechos ocurridos en el Chile en crisis de los años treinta; de tal modo, que muestran lo caótico y absurdo del escenario chileno basado en la hipocresía. En el caso de Marín, el ventrílocuo también es una figura perdida en el pasado que trata de permanecer en "la cultura del desalojo" en la actualidad, sobreviviendo en eventos de poca importancia y con escasez de público, donde la escucha del espectáculo en silencio es más valioso que el habla vacía. En palabras de Maese López: "pasen a oír y a ver... y a hablar, si les da la gana, durante el espectáculo, si señores, podéis hablar cuando os dé la gana. Hablad, hablad, que ya llegará el momento en que nuestras bocas sólo servirán para boquear" (467).

\section{REFERENCIAS}

Alarcón, Catalina. (2013). Germán Marín y su nueva novela: Nació al ver el mundo sumergido en el avance tecnológico. Sitio emol.cl., 26 de agosto. Disponible en: http://www.emol.com/noticias/magazine/2013/08/26/616474/notas-de-un-ventrilocuo-lo-nuevo-de-germanmarin.html.10. Consulta: 10.10.2013.

Blanchot, Maurice. (1992). El libro que vendrá. Caracas: Monte Ávila Editores.

Careaga Roberto. (2013). Soy un outsider a la maraña literaria. Entrevista. La Tercera, 16 de agosto, pp. 48.

Deleuze, Gilles. (1989). El pliegue: Leibniz y el Barroco. Barcelona: Paidós.

Fuentes Leal, Mariela. (2010). En busca del ADN de la escritura en Historia de una absolución familiar de Germán Marín. Acta Literaria, 41, 9-33.

Gandolfo, Pedro. (2013). Un extranjero del ayer. El Mercurio, Arte y Letras, 1 de septiembre, E-16.

Guerrero, Pedro Pablo. (2013). Germán Marín y la literatura como arte menor. Entrevista. El Mercurio, Revista de Libros, 4 de agosto, E. 12.

Huidobro, Vicente. (1967). Poesía y prosa. Antología. Madrid: Aguilar. 2a edición.

Marín, Germán. (1994). Círculo vicioso. Santiago: Planeta. . (1999). Las cien águilas. Santiago: Planeta. - (2005). La ola muerta. Santiago: Random House Mondadori. . (2007). La princesa del Babilonia. Santiago de Chile: Sin Editorial. . (2007). Basuras de Shanghai. Santiago: Random House Mondadori. (2010). Dejar hacer. Santiago: Alfaguara. . (2013). Notas de un ventrílocuo. Santiago de Chile: Alfaguara. 